\title{
THE MAIN CENTERS IN THE TRANSFORMED CITIES AND DEVELOPMENT METHODOLOGY THE CASE STUDY OF SANA,A CITY CENTER
}

\author{
Dr. Khalil Nasher \\ Engineering Faculty, Sana, a University, Yemen \\ e.mail: www. Nasher_unisa@yahoo.com
}

(Received August 20, 2006 Accepted September 2, 2006)

\begin{abstract}
Rapid urban growth in cities, particularly in major cities occurs, wherever the urban mass be doubled, and city core size be stopped. That will lead to unbalanced relation between the center and the extended area of the city.

The research problem is that the existing Sanaa main center has not coped with the changes of the city. The center has remained rigid and non functional nucleus, and unable to supply the demand of its arteries by blood, and from the other side its extremities could not feed it.
\end{abstract}

The research aimed to answer a specific question: If the Tahrir square is still considered the main urban center of the transformed capital? If so, does it successfully feed its extended edges, or the need to a new center still recommended

To answer the main question, the structural, analytical, methodology has bee chosen and the result was; that if the city has been widely developed, it will be necessary to promote its old center and support it by creation a new center in an appropriate central location, in addition to strengthen the existing sub-centers as well.

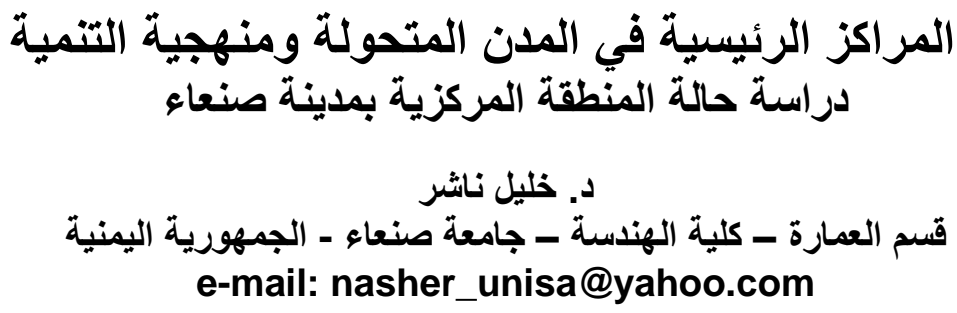

الملخص

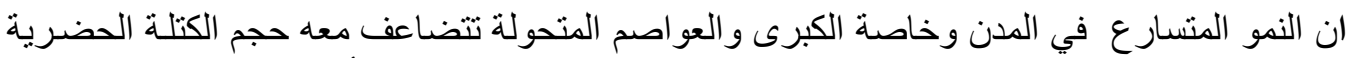

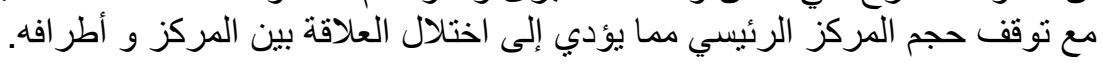
تتمثل مشكلة البحث في أن المركز الحالي لمدينة صنعاء لم يو اكب التحول في النمو أي ظل مركزهـا

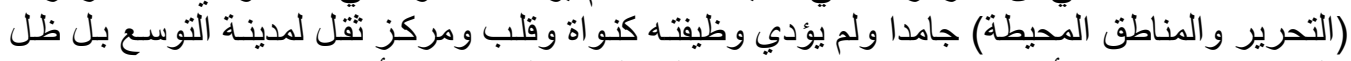
على استحياء من بقية أطر افه فلا هو يمد شر أيينه بالدم الكافي المتدفق ولا لا أطر افه تغذيه. 
يهدف البحث للإجابة على سؤال محدد ألا وهو هل منطقة التحرير تعتبر المركز الحضري الرئيس إعليس

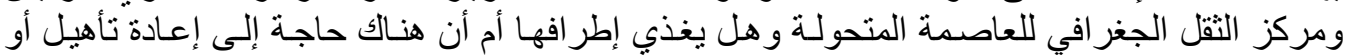
خلق مركز حضري جديد ليو اكب النمو المتحول.

وصو لا إلى الإجابة على التساؤل الذي يطرحه هذا البحث تم اختيار المنهج الإنثـائي التحليلي لعناصر

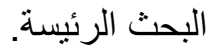

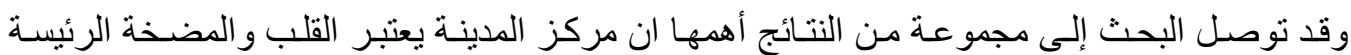

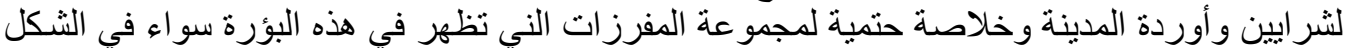

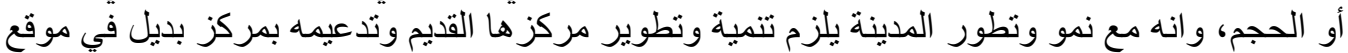

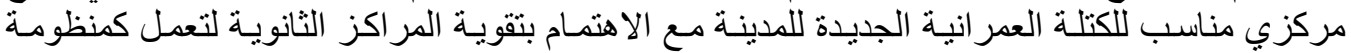
متوازنة ومتكاملة.

كلمات مفتاحيه: صنعاء - مر اكز مدن - مدن تحول - نواة وقلب- تنمية وحفاظ.

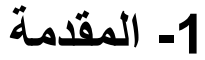

في كثير من الأحيان يتدخل القرار السياسي في التأثير على تحديد موقع مركز المدينـة الرئيسي

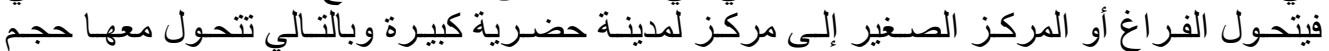
ومكونات ووظيفة هذا المركز ليفي بمتطلبات المركز الحضري الجرئ الجديد.

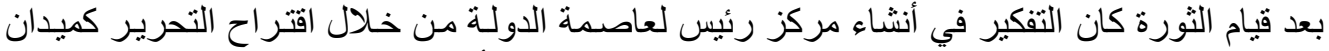

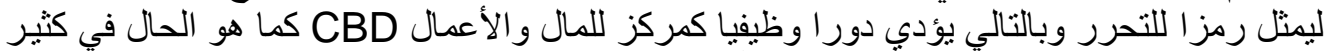

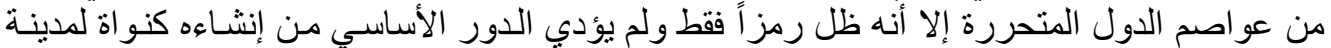

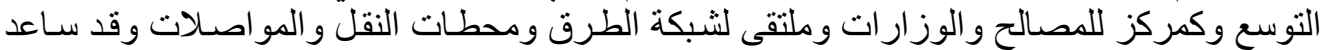

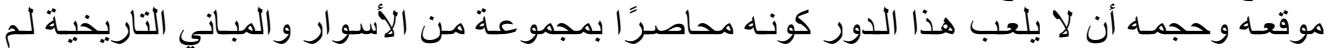

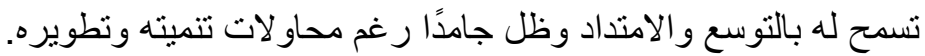

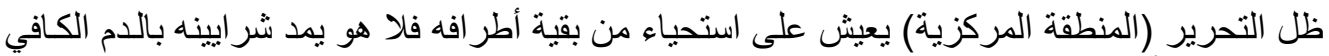

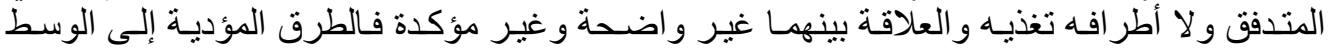
(القلب) ضعيفة وصغيرة بل ومتعرجة و لا تصب فيه واله وحجم القلب غير مناسب لحجم الجسد.

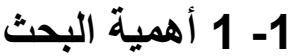

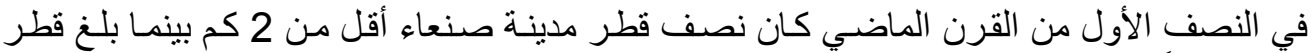

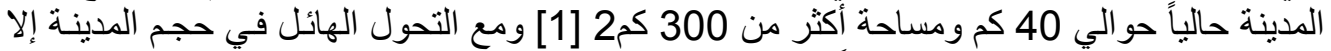

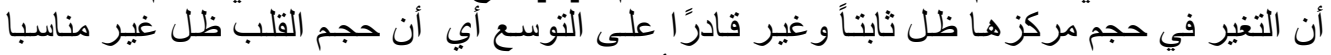

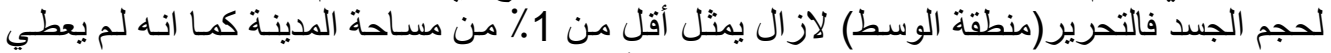

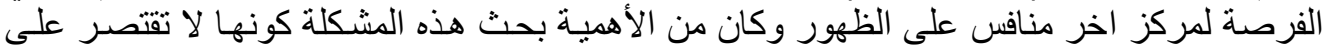

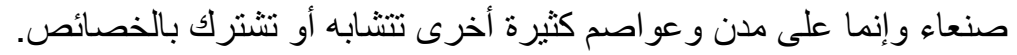

\section{1- 2 المشكلة البحثية}

قلب المدينة الحالي ( منطقة ميدان التحرير) ظل بقاؤه ضرورة حتمية كمركز لتجميع الأنشطة الكييرة

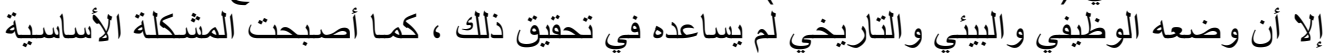


في المنطقة المركزية الحالية بيئية ومثكلة حركة تحولت إلى عقدة مروريـة كبيرة ، كما أن في حسال

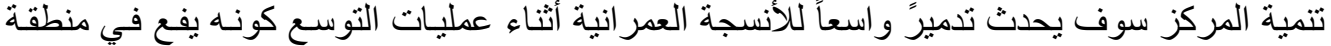

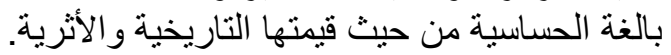

\section{| - - 1-1 منطقة الدراسة}

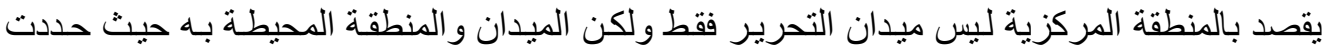

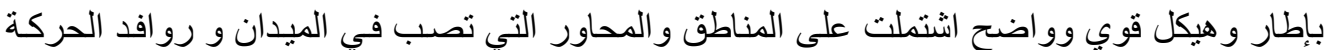

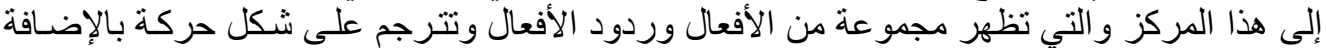
إلى المباني المحبطة وتأثير اتها المستقبلية على حجم المركز وشكل وشكله الثكل (1).

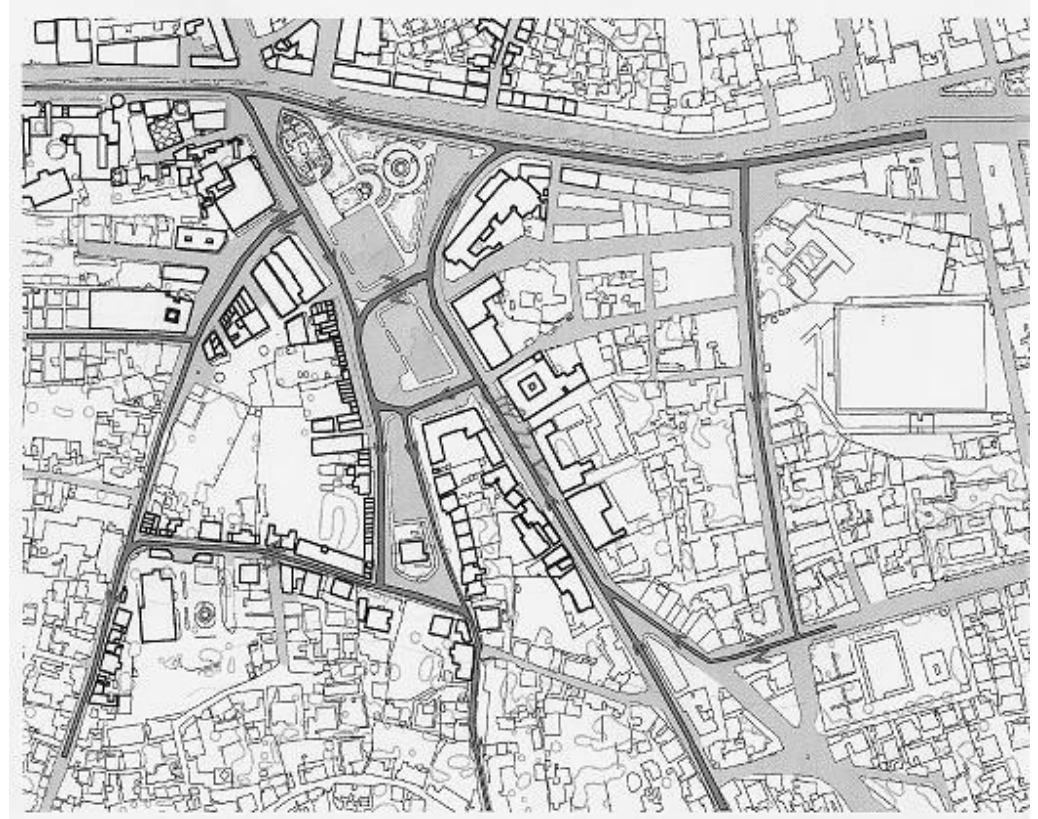

الثكل (1): منطقة الدراسة.

\section{2- المفهوم التخطيطي للمراكز الحضرية في المدن}

لغرض البحث سوف يتم التركيز على التفريق بين الفراغـات الحضرية بمفهومها المعاصـر و أيضـا بمفهومها التقليدي القائم في المدينة اليمنية ومنها العاصمة صنئ لفنعاء على النحو التالي:

1-2 المفهوم المعاصر للمراكز: وظهرت إما على شكل المركز الرئيسي للمدينة أو المر اكز الثانوية كالتالي:

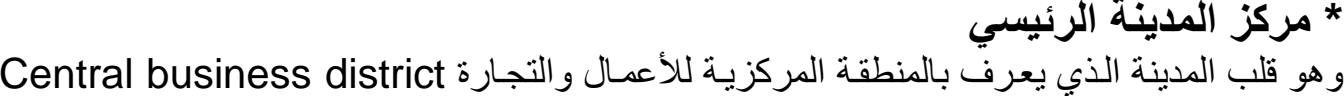
وتختصر باسم (CBD) أو ( down town ) و عموما فان قلب المدينة الكبرى يعني المكان الأكثر 


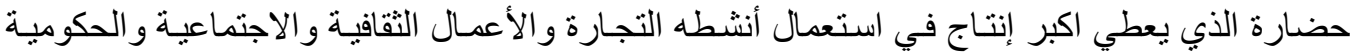

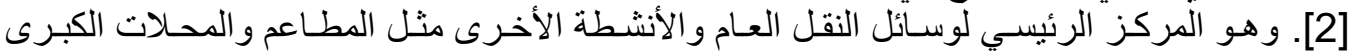

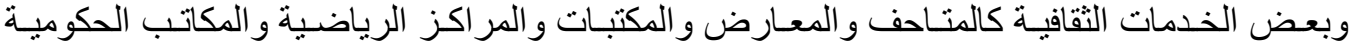

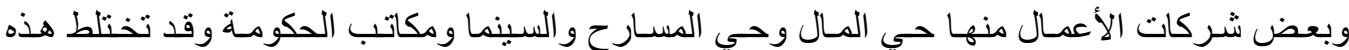

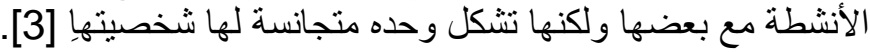

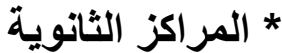

ظهر الفر اغ الحضري المعاصر بإنشكال متعددة حسب الموقع و الوظيفة التي يقدمها مثل مركز المجاورة السكنية أو مركز الحي أو مركز القطاع.

\section{2-2 المفهوم التقليدي للمراكز الحضرية في مدينة صنعاء:}

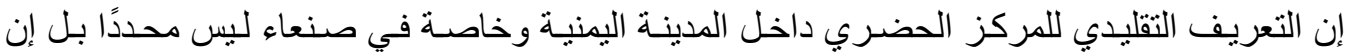

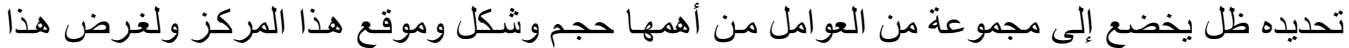
البحث يمكن التركيز على الفر اغات الوظيفية (المر اكز) التالية:

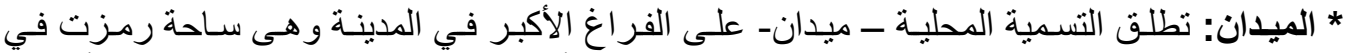

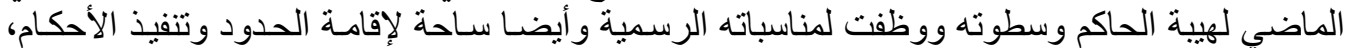

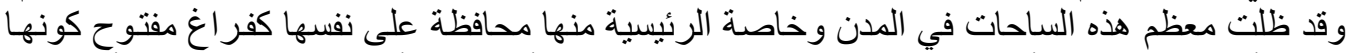

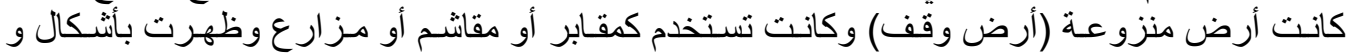

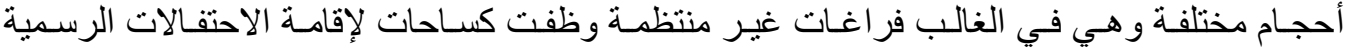

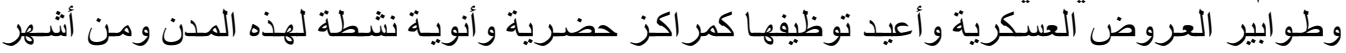
الميادين في صنعاء ميدان التحرير ( منطقة الدراسة) وميدان السبعين.

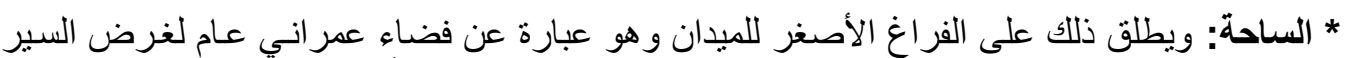

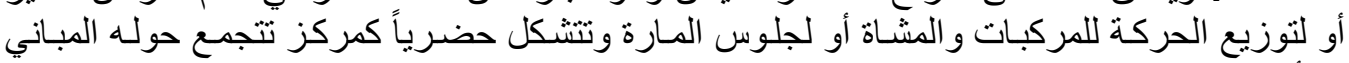
والأنشطة ومنها ساحة الميدان الرياضي وساحة الكلية الحربية [4].

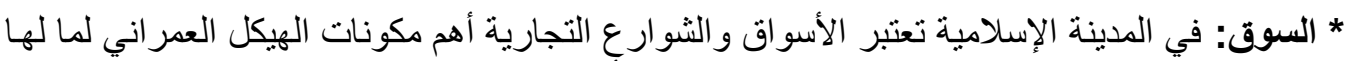

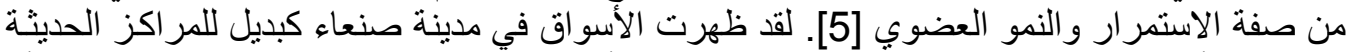

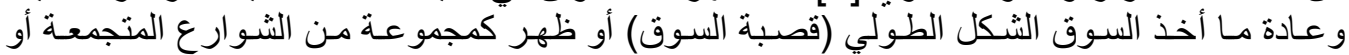

كفضاء أو كثار ع أو كالمكان الو اسع المفتوح أو اعتبر السوق كنو الة للمدينة ( سوق الملح) [6].

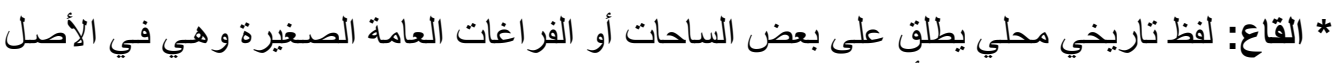

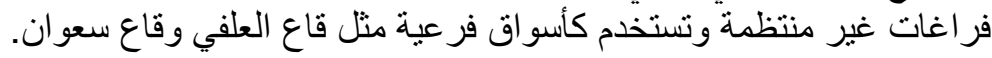

\section{3- منهجية التحول في المدن ومراكزها}

تنو عت مشـاكل التحول للمدن في مجموعـة من الإشكال و الاتجاهـات كان للمركز الرئيسيسي للأنشطة

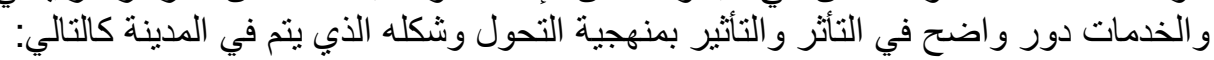

\section{1-3 التحول في المدينة وعلاقتها بالمركز الرئيسي}

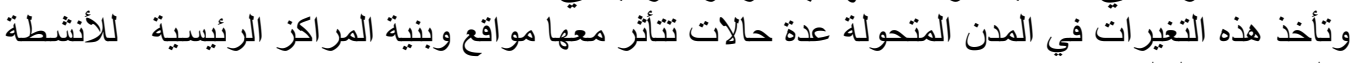

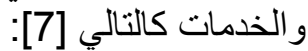


ـ قد يشمل التغير مكونات مو اقع مختلفة من الهيكل العمر اني داخل الحيز الحضري وفي وفي هذه الحالة يسلك المركز الرئيسي نفس السلوك ويكون التغير في نفس حدود وحيز المركز ودون تغيير في نمطس

التخطيطي.

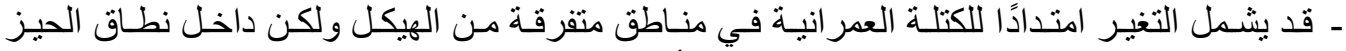

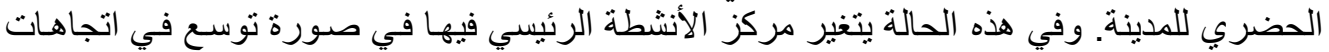
محددة تأخذ شكل النمو و الامتداد.

ـ قد يكون نمو المدينة و امتدادها في شكل تجمعات خارج الحيز الحضري ( ضو احي احي) وفي هذه الحالة يكون التغير على شكل مر اكز فرعية ذات ارتباط قوى بشبكة من الطرق بالمركز الرئيسي المئي للمدينة.

\section{2-3 اشكال التحول في المراكز الرئيسية للمدن}

التحول في مر اكز الأنشطة والخدمات بالمدينـة يتم من خـلال علاقـة النمو والامتداد في المركز باتجـاه النمو أو التنمية للمدينة نفسها [8] وتتم في واحدة من الحالات التالية:

ـ نمو المركز في نفس اتجـاه امتداد نمو المدينـة ولكنـه على حسـاب التغيير لبعض استعمالات الأرض لمنطقة امتداد ألمركز داخل نفس حيز المدينة. ـ نمو المركز و المدينـة معـاً نمـوًا متمركزًا ويشـمل التغير في المركز نطـاق الامتداد داخل نفس الحيز الحضري للمدينة. ـ نمو المركز في شكل إنشـاء مركز اخر جديد خـاص بمنطقة الامتداد وفي نفس اتجـاه امتداد التنميـة للمدينة. ـ نمو مركز المدينة في شكل مركز أخر جديد للمدينة التوأم للمدينة الأم. وتكون الأنشطة و الخدمات في المركز الجديد مكملة لعناصر مركز مزئة مركز المدينة الأم.

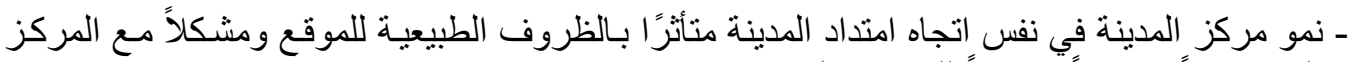

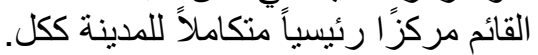

\section{4- التحول البنيوي لمركز مدينة صنعاء}

تعتبر در اسة التحول البنيوي للمركز الرئيسي في العاصمة صنعاء من المؤشـر ات الهامـة لتحديد مسـار

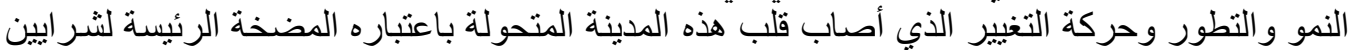

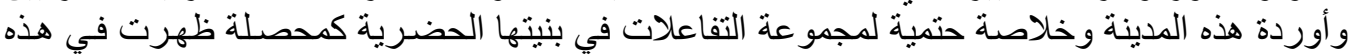
البؤرة وكانت هذه التحو لات قد مرت الته بمر احل متو الية كالتالي:

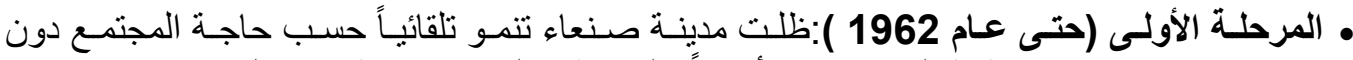

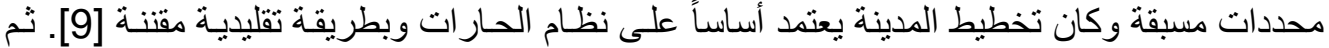

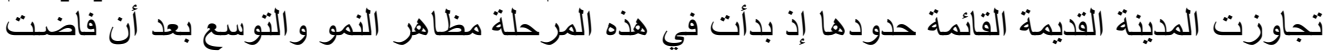

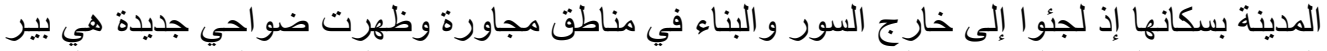

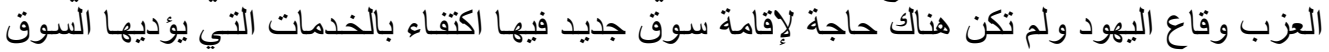

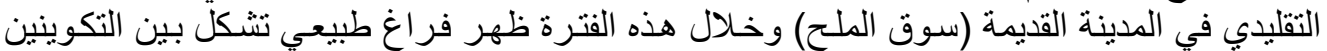

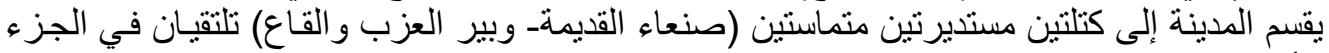

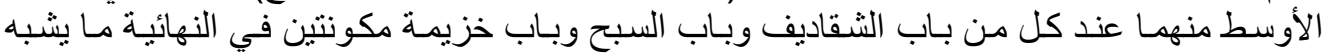

المسنطيل غير المنتظم أطلق عليه فيما بعد مبدان التحرير الثكل (2). 


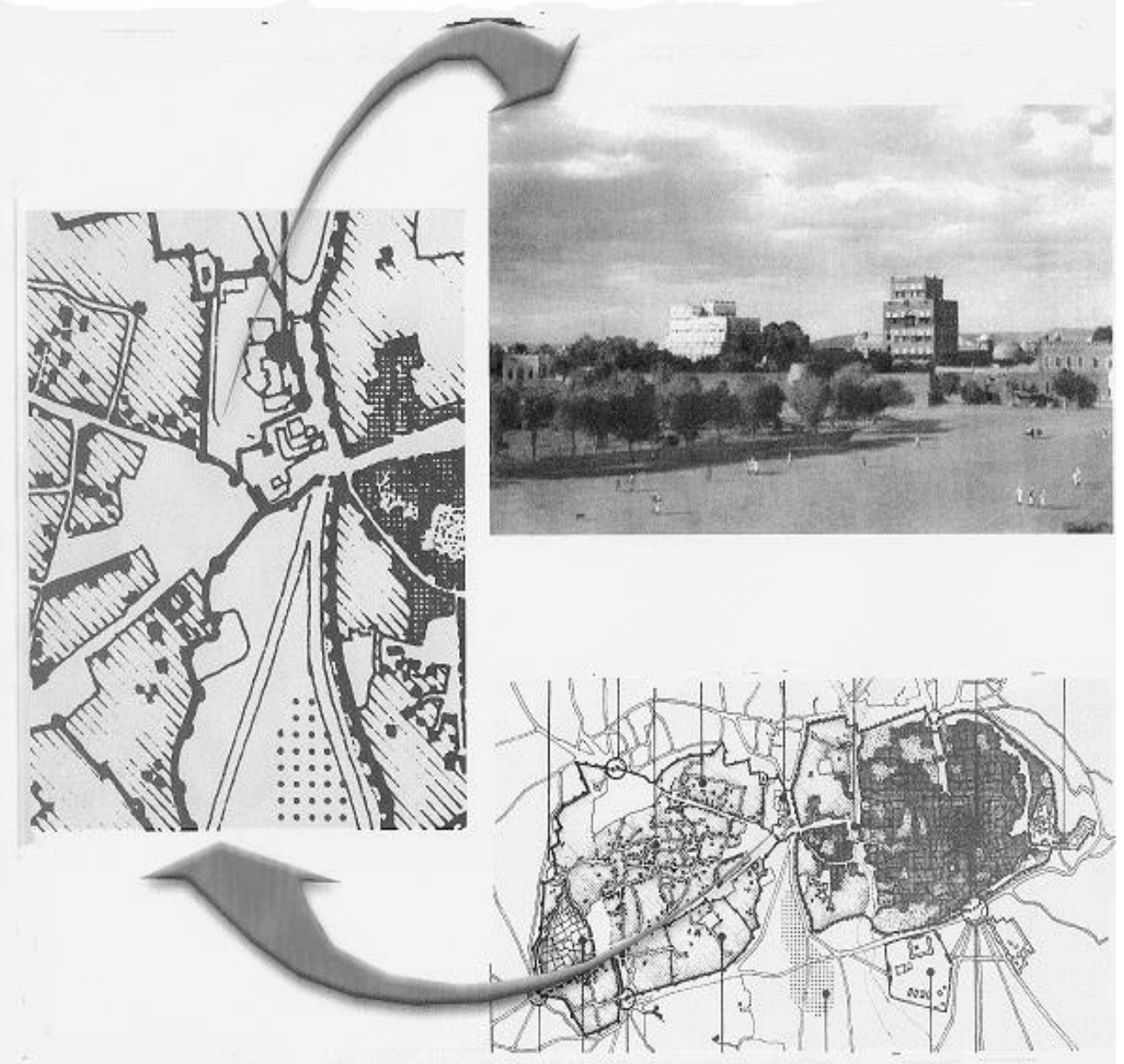

الثكل (2): مدينة صنعاء وفر اغ التحرير كمركز لها في بداية التكوين.

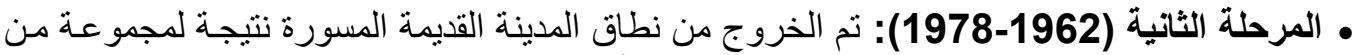

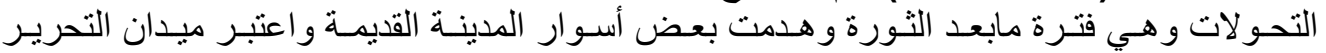

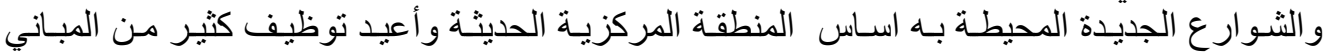

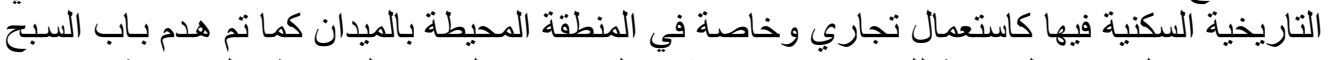

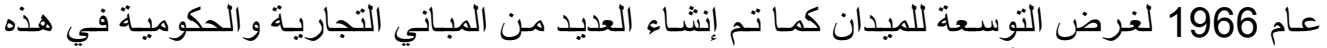

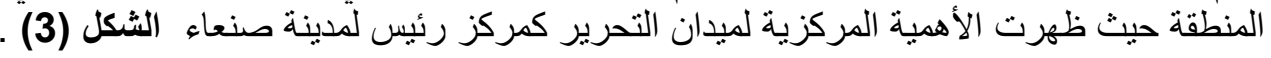
• المرحلة الثالثة (1978-1990): في العام 1978 تم إعداد أول مخطط عام لمدينة صنعاء بواء اسطة

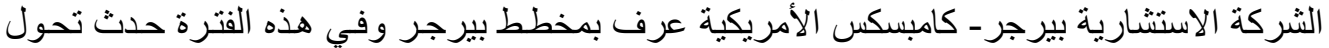

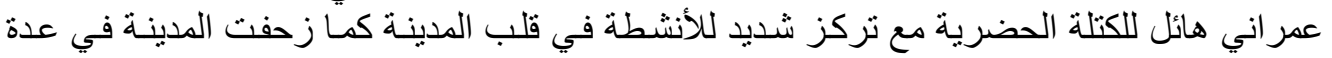
اتجاهات ومحاور على شكل طرق وشر ايين إقليمية خارجة جميعها من نو اة المركز الافتراضية.

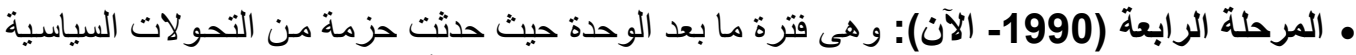

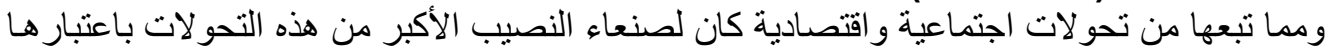


عاصمة الدولة الموحدة تجاوزت الكتلة الحضرية حدودها في مخطط بيرجر لعام 2000 بنطاق و اسع العابع

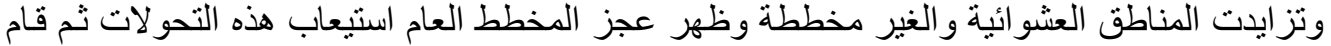

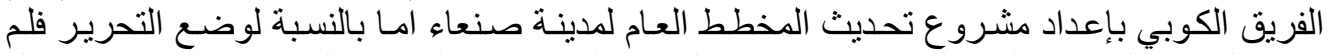

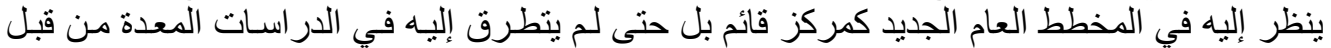
الفريق.

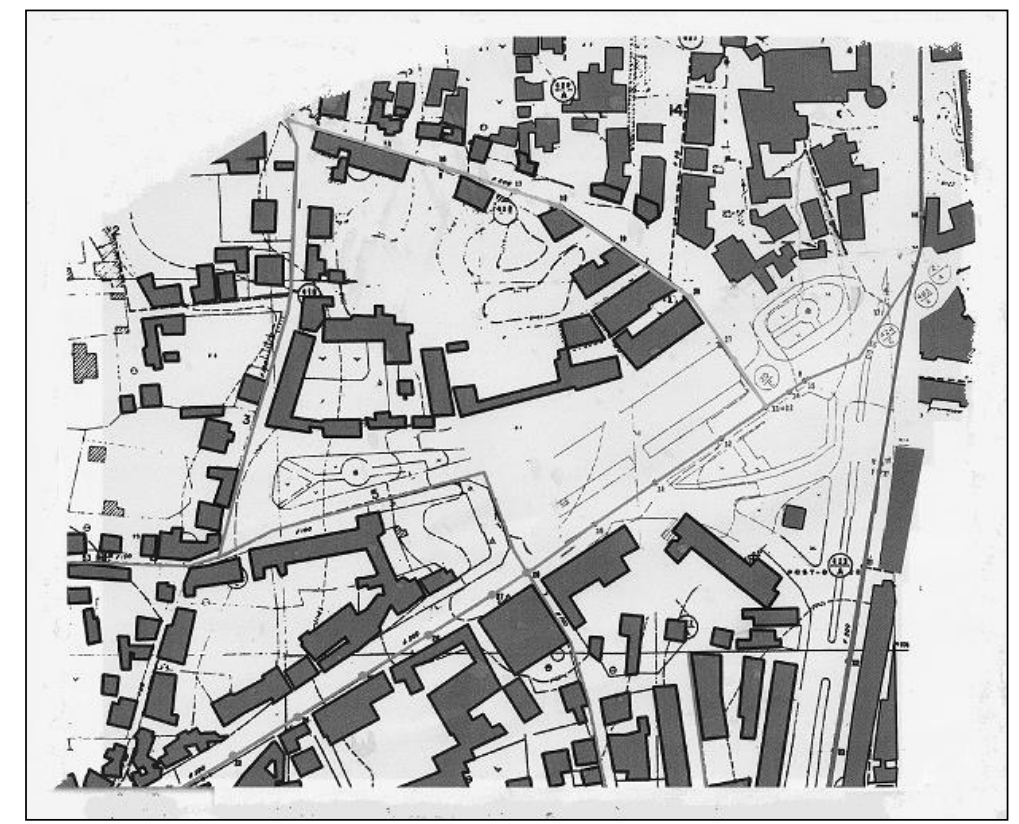

الشكل (3): التحرير كميدان ومركز لمدينة صنعاء كما ظهر في المرحلة الثانية.

\section{5- المحاولات التخطيطية لنظوير المركز}

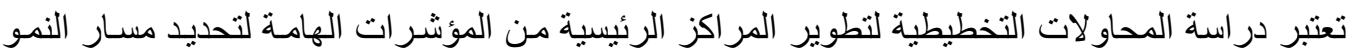

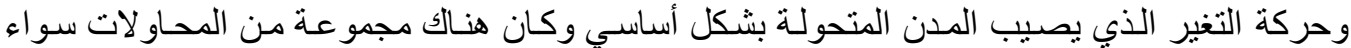
لتنمية المركز القائم أو إعادة تأهيله أو التفكير في خلق مركز جديد كالتالي:

\section{1-5 مقترح بيرجر لتطوير المنطقة المركزية :}

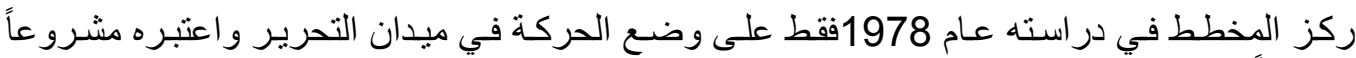

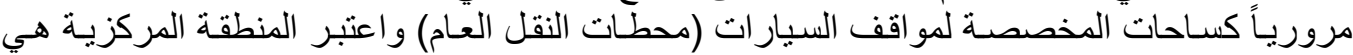

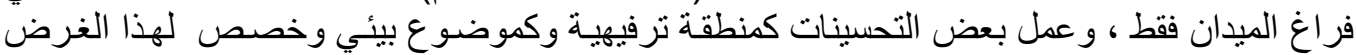

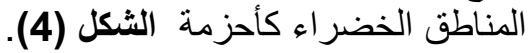
كما اقترح بيرجر مركزه الجديد البديل للتحرير شمالا في منطقة الحصبة بمسـاحة حو الي 200 هكتار

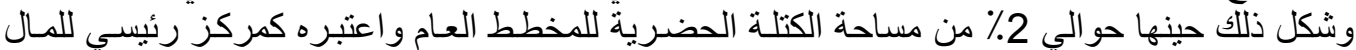

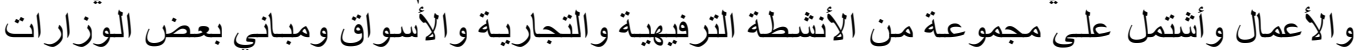

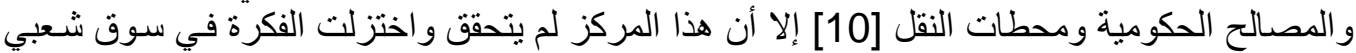
وبعض المصالح الحكومية مثل وزارة التموين ومصلحة المساحة. 


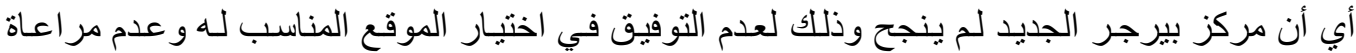

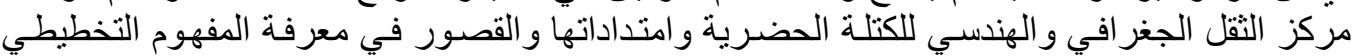
للمر اكز في المدينة اليمنية.

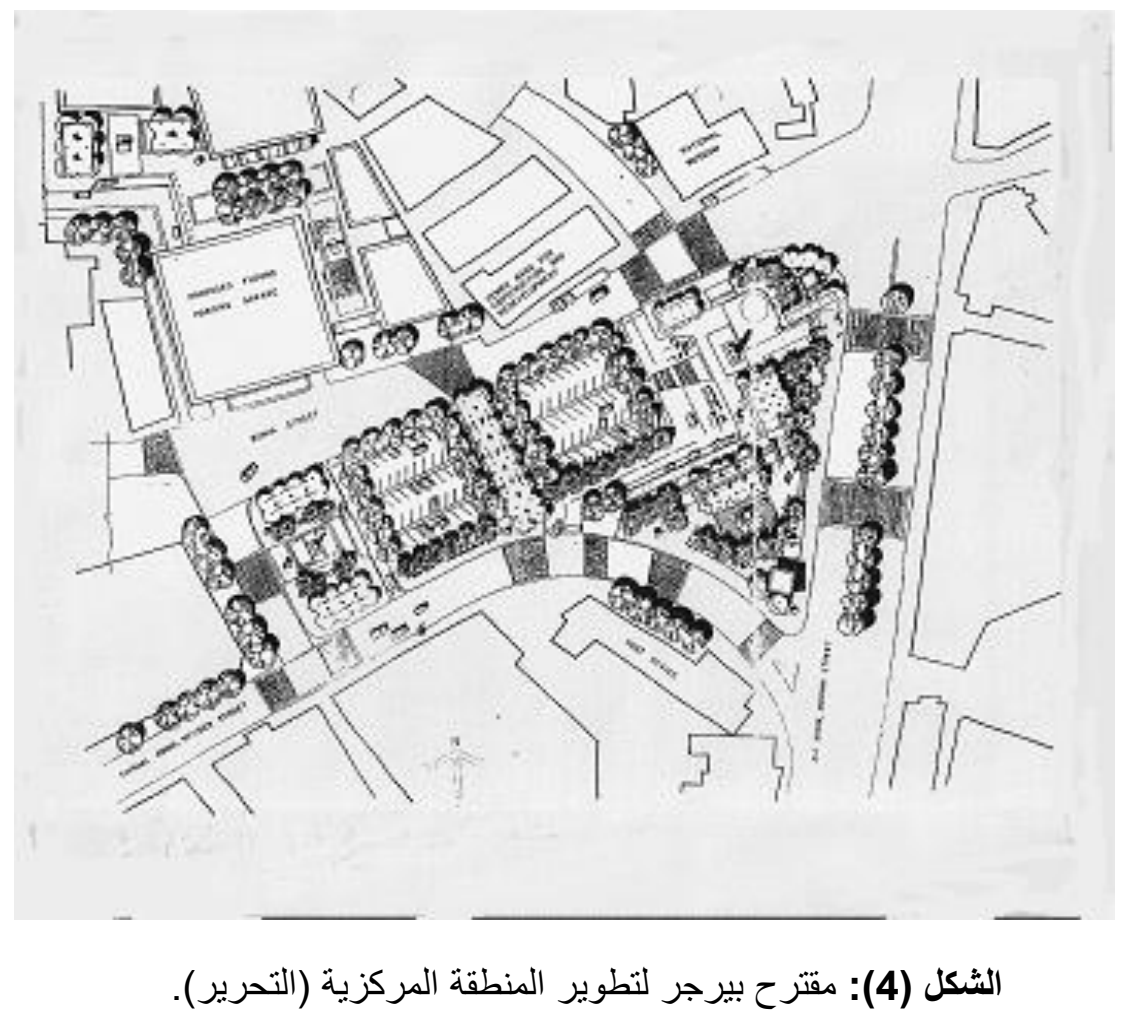

\section{2-5 مركز الفريق الكوبي ووضع المنطقة المركزية}

في مشروع المخطط الهيكلي لمدينة صنعاء الذي أعده الفريق الكوبي الاستشـاري بوز ارة الإسكان عام

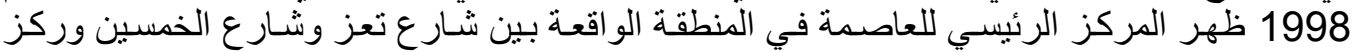

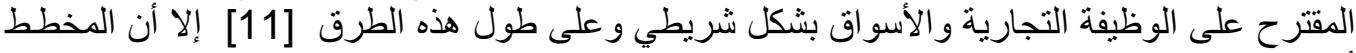

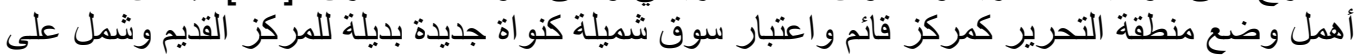

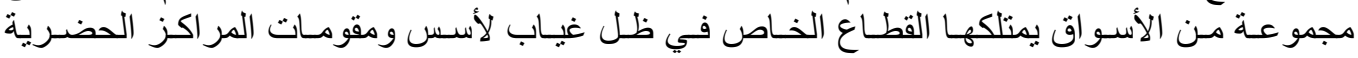
و الفر اغات و الوظائف المركزية الفية.

\section{3-5 محاولات أخرى لتطوير منطقة المركز}

في الغالب كانت و لا تز ال هنالك محاو لات شكلية لتطوير منطقة مركز مدينة صنعاء وفي جميع المر احل

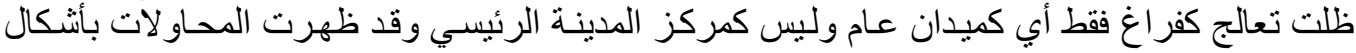

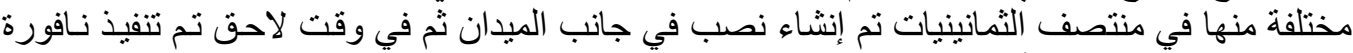

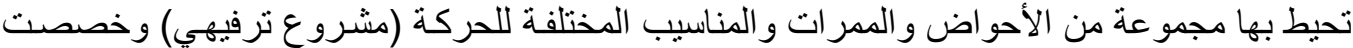
ساحة للعروض الاحتفالية في أعياد الثورة وكذلك خصصت منطقة وسطية كمحطة للسبيار ات الأجرة 


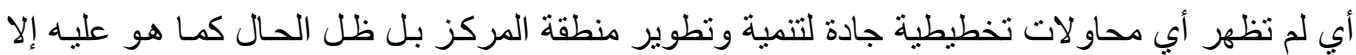

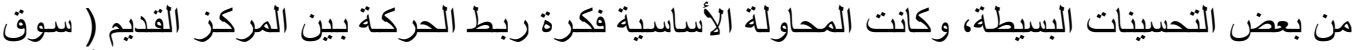

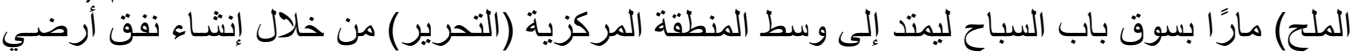

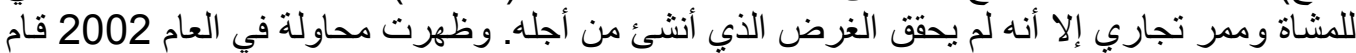

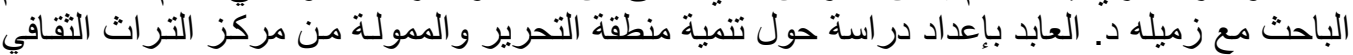

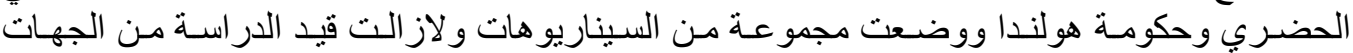

الرسمبة.

\section{6- هيكل ووظيفة المر اكز في صنعاء}

يمكن تصنيف المر اكز في مدينة صنعاء و اختز الها قي نو عين أساسين فقط كالتالي:

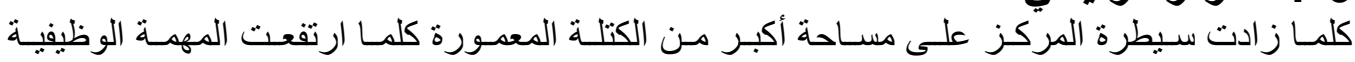

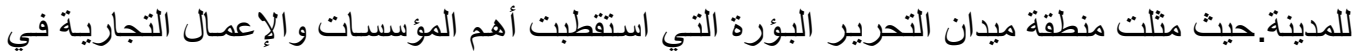

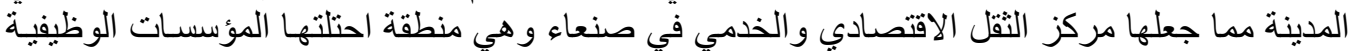

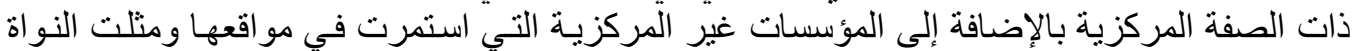
الأولى والمركز المفة الرئيسي للمدينة.

حيث تسـقطب هذه المنطقة أكبر عدد مـن المؤسسـات التجاريـة إذ بلـغ عدد المؤسسـات التجاريـة فيها

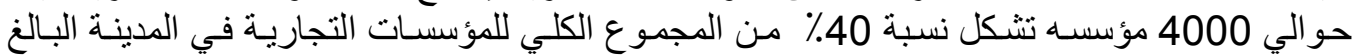

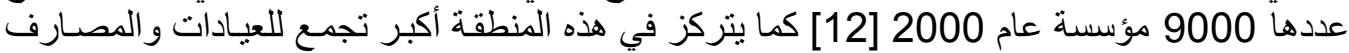

و المطاعم و الخدمات الأخرى و التي تتصف عام بوظائف ذات طبيعة مركزية.

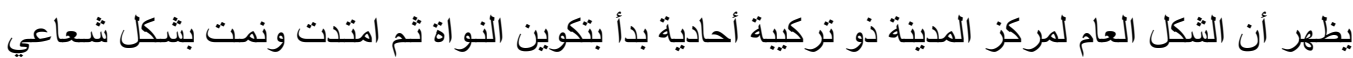

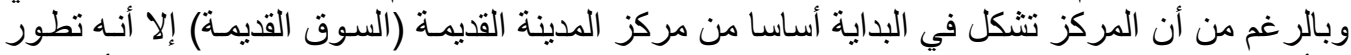

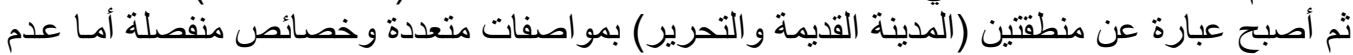

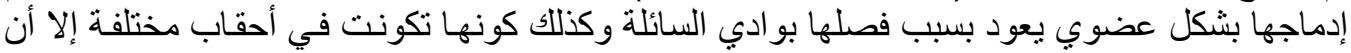
هذين الجزئيين يؤديان وظيفة واحدة [13:

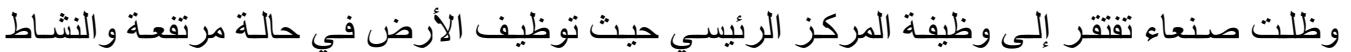

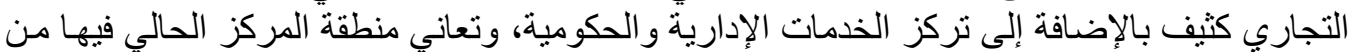

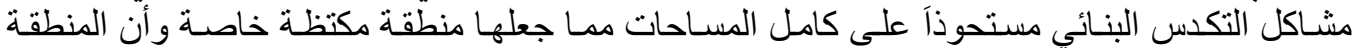
محاطة بالمباني التاريخية ذات القيمة الأثرية مما يصعب التئ تنميتها أو توسعتها.

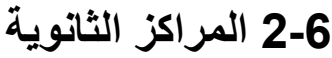

تتوزع الخدمات العامة على المر اكز في المدينة بشكل غير مقنن وتظهر الخدمات متجمعة في المنطقة

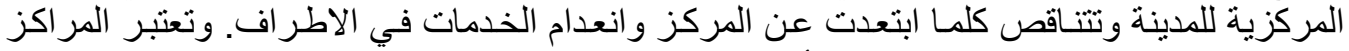

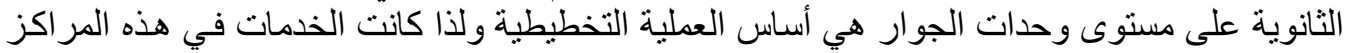

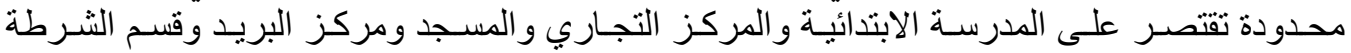

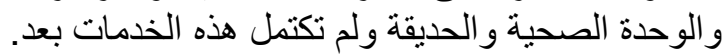

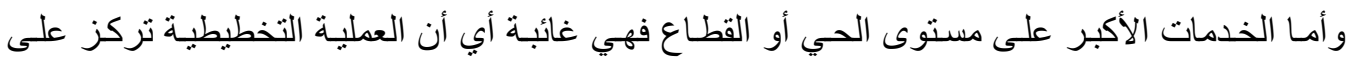

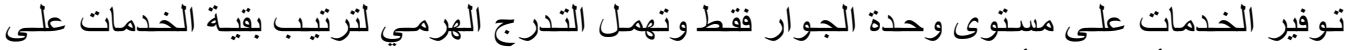
مستوى الحي أو القطاع أو المدينة.[14 


\section{7- منهجية توزيع المراكز في مدينة صنعاء}

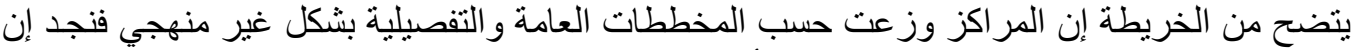
المر اكز تعددت مو اقعها و إحجامها و إثكالها و أنو اعها بشكل عشو ائي و غير مقنن ويظهر مركز المدينة المدينة (التحرير) النواة الأصلية و القطب التجارئ التجاري النشط.

\section{1-7 مواقع المراكز}

تناثرت مو اقع هذه المر اكز على طول الكتلة العمر انية وظهرت بشكل غير مدروس و غير مقنن فأحيانا

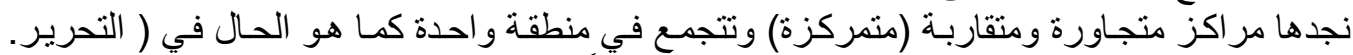

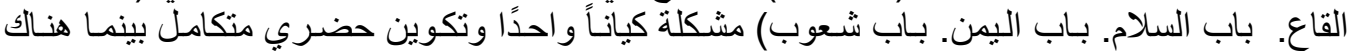

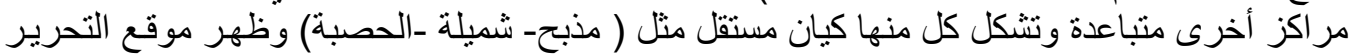

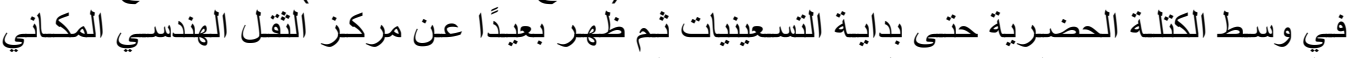

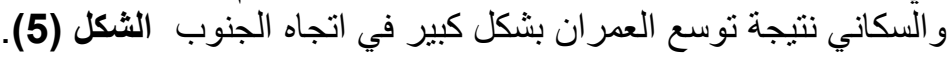

\section{2-7 أحجام المراكز}

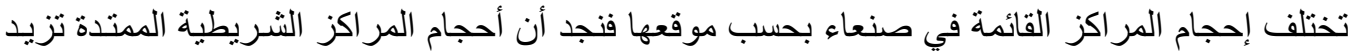

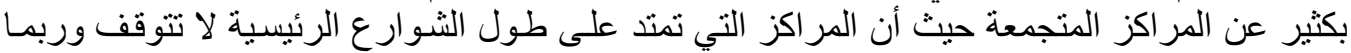

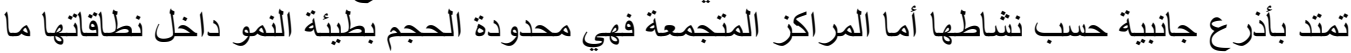
عدا منطقة وسط المدينة (التحرير) فقد ظهرت أكثر نشاطا وحركة وظهرت كبرة كبيرة الحجم نسبيا مقارنـة ببقية المر اكز النشطة الأخرى.

\section{3-7 أثكال المراكز}

تشكلت المر اكز قي مدينة صنعاء حسب الحاجة وحسب ملكية الأرض ولم تستطع المخططات المعتمدة

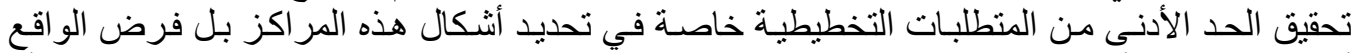

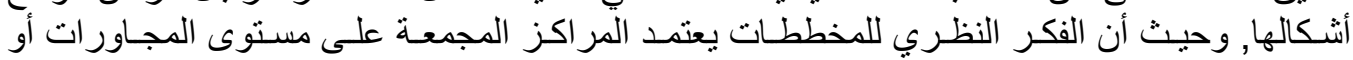

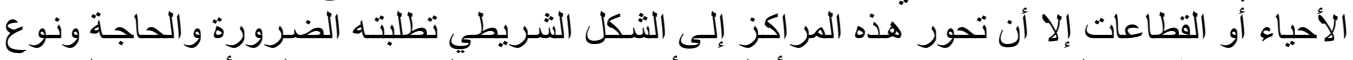

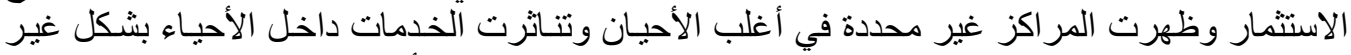

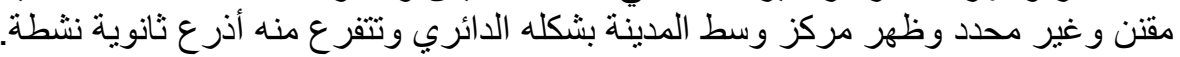

\section{8- التصنيف الوظيفي للمراكز الرئيسية في المدينة}

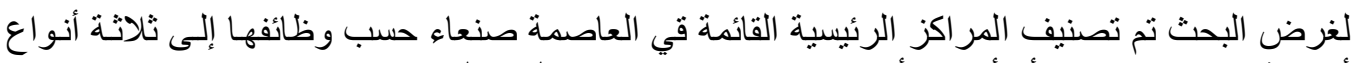

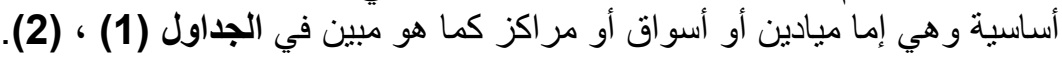

وكنتيجة للتوصيف المبين في الجداول (1) و (2) يظهر التحرير ( المنطقة المركزيـة) منطقة مهيمنـة

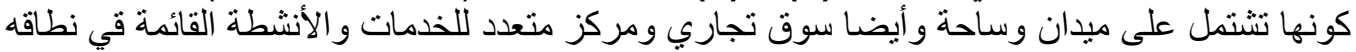

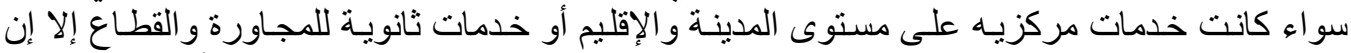

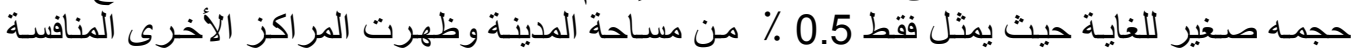

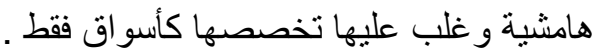




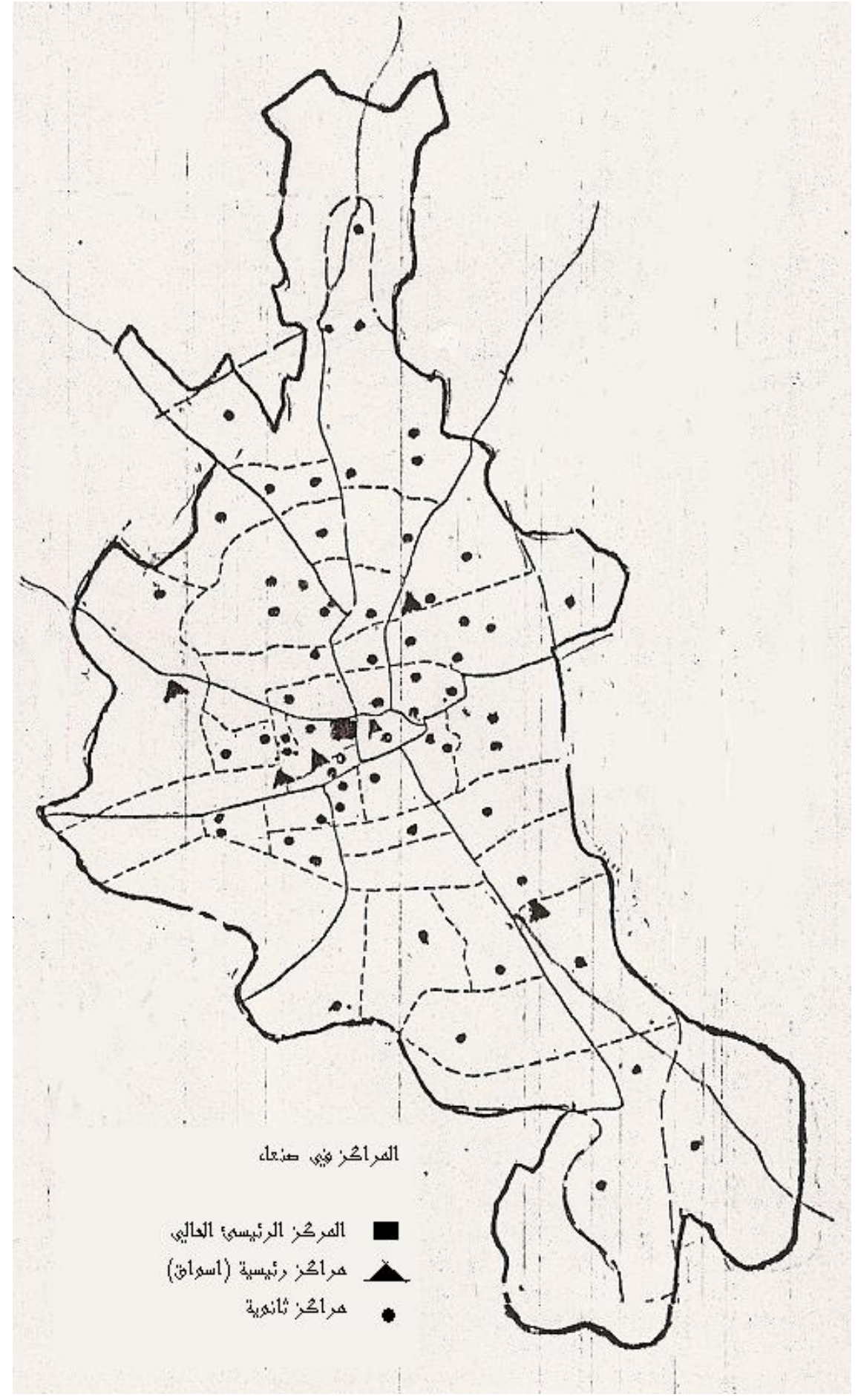

$$
\text { الثكل(5): المر اكز التضرية التخطيط العمر مدينة صنحاء. }
$$


المصدر: الباحث

الجدول(1): التصنيف الوظيفي للمراكز الرئيسية في صنعاء.

\begin{tabular}{|c|c|c|c|c|c|c|c|c|c|}
\hline \multicolumn{5}{|c|}{ مراكز } & \multicolumn{2}{|c|}{ أسواق } & \multicolumn{2}{|c|}{ ميادين } & \multirow[t]{2}{*}{ التصنيف } \\
\hline إقليم & مدينة & قطاع & حي & مجاورة & جملة & تجزئة & ساحة & ميدان & \\
\hline * & * & * & * & * & * & * & * & * & التحريز \\
\hline & & & & & & * & * & & القاع \\
\hline & & & & & * & * & * & & باب القاع \\
\hline & & & & & * & * & * & & باب السلام \\
\hline & & & & & * & * & & & شعوب \\
\hline & & & & & * & * & & & باب اليمن \\
\hline * & & & & & * & * & & & الحصبة \\
\hline * & & & & & * & * & * & & شميلة \\
\hline * & & & & & * & * & & & مذبح \\
\hline
\end{tabular}

المصدر: الباحث

الجدول (2): إحجام المر اكز الرئيسية.

\begin{tabular}{|c|c|c|c|c|c|c|c|c|c|}
\hline مذبح & شميلة & الحصبة & اليمن & شعوب & السلاب & القاب & القاع & التحرير & التصنيف \\
\hline 40 & 30 & 30 & 20 & 40 & 5 & 40 & 30 & 150 & |المساحة/ هكتار \\
\hline 0.13 & 0.1 & 0.1 & 0.06 & 0.13 & 0.01 & 0.13 & 0.1 & 0.5 & النسبة \% للمدينة \\
\hline
\end{tabular}

\section{9- استعمالات الأرض في المنطقة المركزية}

قام الباحث بمسح استعمالات المباني قي منطقة التحرير ونم التركيز على المباني الو اقعة على المئى المحاور

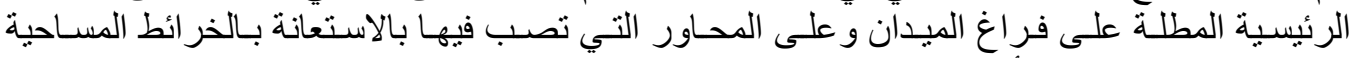
واختزل التوصيف بشكل أساسي كالتالي:

\section{1-9 الاستعمال السكني:}

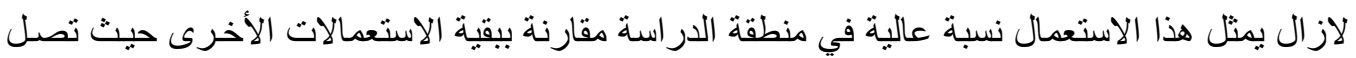

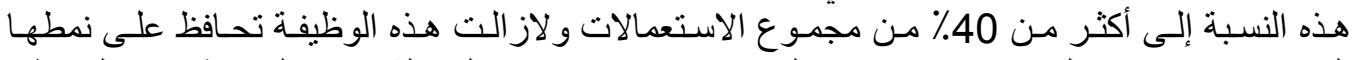

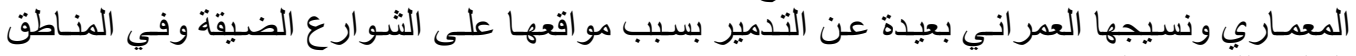

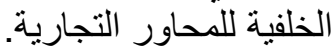

\section{2-9 - 2-9 الاستعمال التجاري:}

يشغل هذا الاستعمال قلب المنطقة المركزيـة ويمثل النشاط الأبرز من الأنشطة الاستئنمارية في منطقة

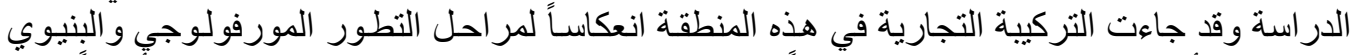

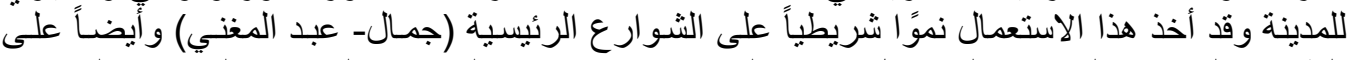

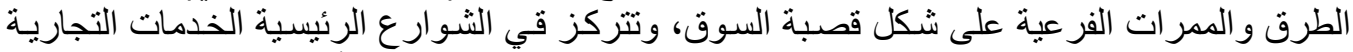

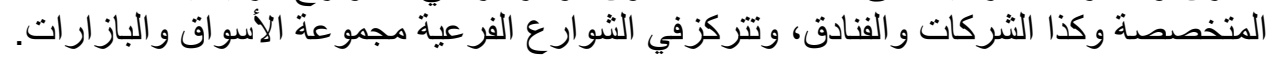




\section{3-9 الاستعمال الحكومي والإداري}

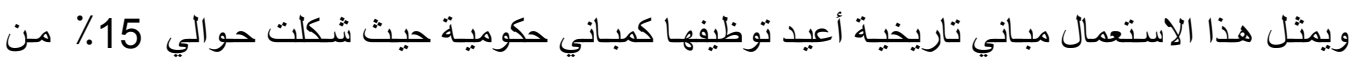

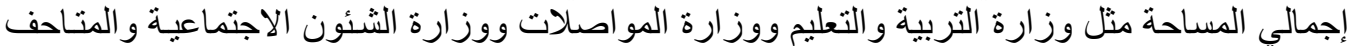

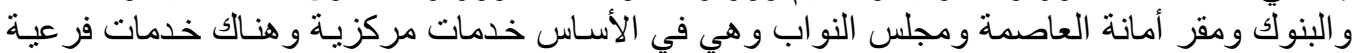

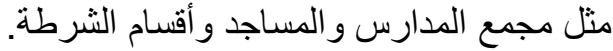

\section{4-9 الفراغ الحضري للميدان}

و هو عبـارة عن سـاحة محدودة جداً لا تزيد مسـاحتها عن نصف هكتار وبـه حديقة وسطية ومحطسة

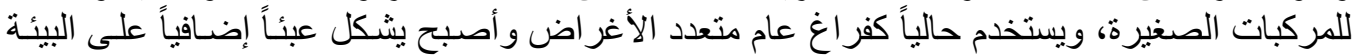
الحضرية كونه أصبح منطقة لتجمع الزئرين وائر والباعة عام المتجولين و المتسولين.

\section{0- مركز الثقل والمقومات المكاتية}

الغرض مـن معرفة مركز التقل السكاني في مدينـة صنعاء هو كونها تعتبر إحدى الوسـائل الأساسية

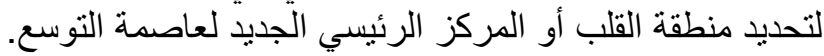
إن التعرف على اتجاه حركة السكان بما يؤثر في اتجاهات نمو المدينة يتم ذلك مـن خلال معرفة النقطة

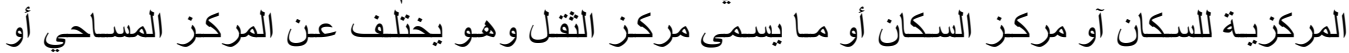

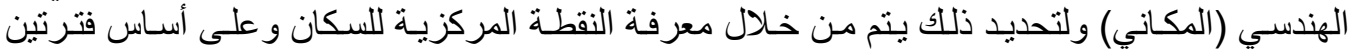
تعداديتين بإتباع الخطو ات التالية:[15] ـ ـ يتم رسم خريطة مفصلة للوحدات الإداريـة وتوفير بياناتها السكانية وتحديد مركز السكان في كل يتم رسم محورين احدهما راسي والأخر أفقي ويتقاطع المحوران بزاوية قائمسة إلى الجنوب الغربي من كتلة المدينة. يعد جدول يكتب به في العمود الأول أسماء الوحدات الإداريـة وفي العمود الثاني سكان كل وحدة

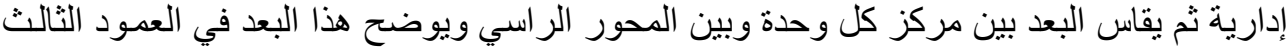

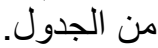
يسجل في العمود الرابع من الجدول حاصل ضرب الجرب عدد سكان الوحدات التعداديـة في البعد بين

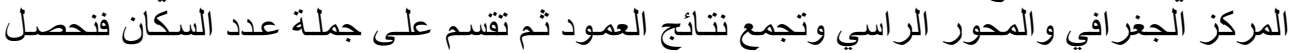
على رقمة ما.

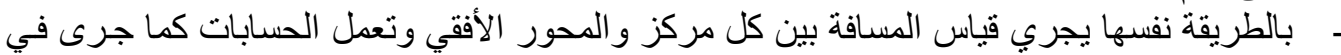
حالة المحور الر اسي ثم تقسم نتائج العمود على جملة السكان فنحصـل على رقم ثنان كمـا كان فيمـا ـ الرقمان اللذان نحصل عليهما من الخطوتين يمثلان المسافة التي يجب انتقال المحوران إليها ونقطـة تقاطع النقطتين هو مركز الثقل السكاني للمدينة.

\section{1-10 مركز الثقل السكاني لمدينة صنعاء}

تم التوصل لمركز العاصمة صنعاء السكاني باستخدام الخطوات السابقة وبالاستعانة بالتعدادين للوحدات

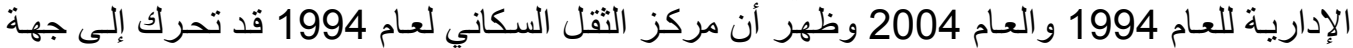

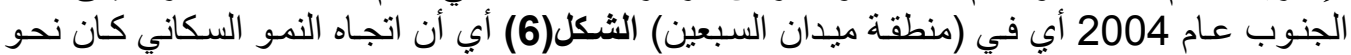

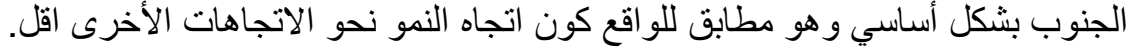




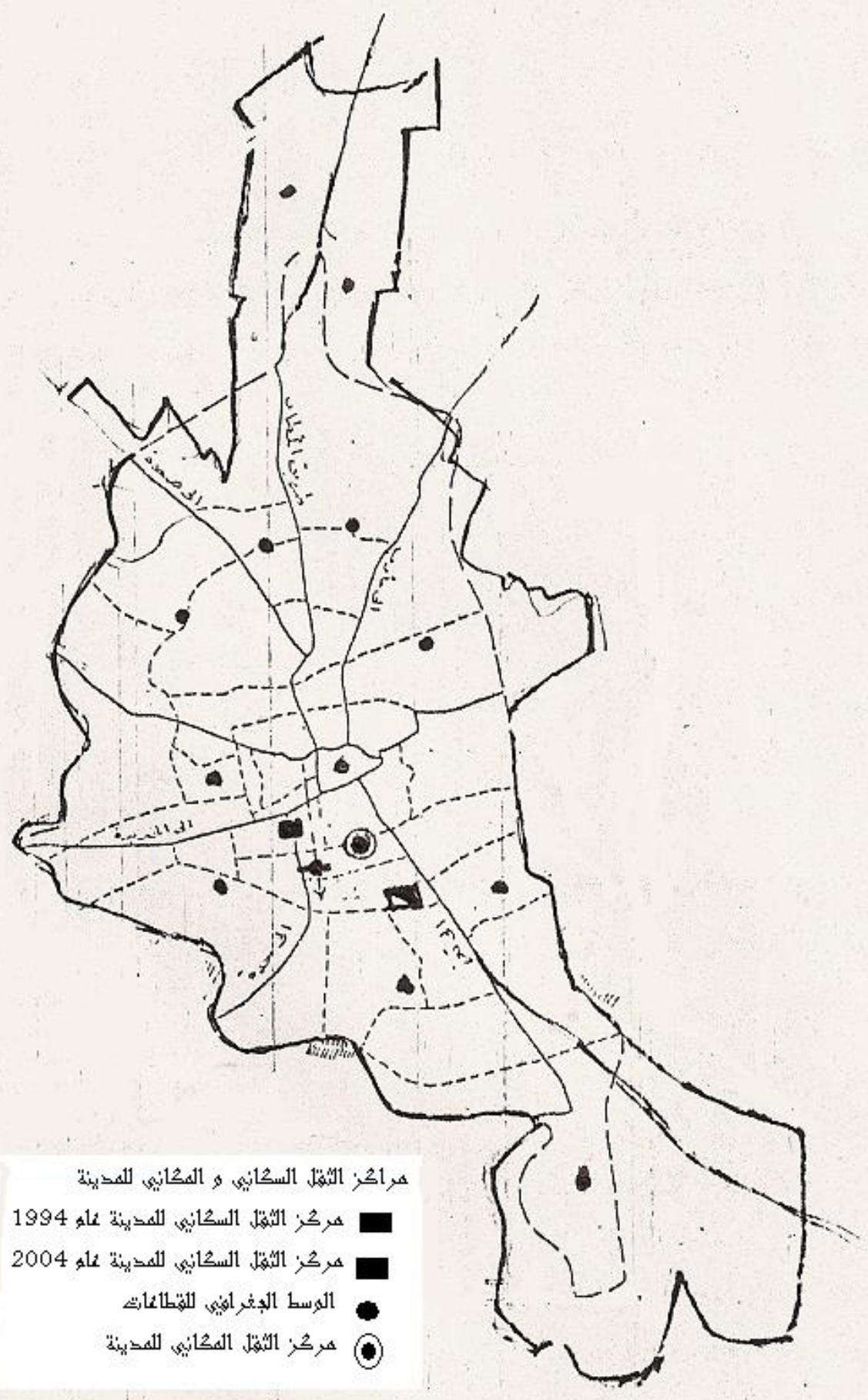

الشكل (6): مر اكز الثقل السكاني و المكاني لمدينة صنعاء. المصدر : الباحث 


\section{2-10 مركز الثقل الهندسي المكاني}

مركز الثقل المكـاني ظهـر أيضـا في نفس مركز الثقل السـكاني تقريبـا كمنطقة وسطية بـين الثـمال

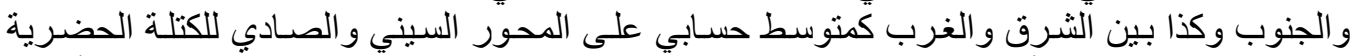
الحالية ويتضح من ذلك أهمية هذا الموقع كمركز رئيسي بديل بالإضافة إلى مجمو عة المقومات الأخرى ومؤكداً لها.

\section{1- المقومات المكانية الحضرية لمركز الثقل}

ظهرت مجمو عة من المقومات لمركز لنقل الجديد كتأكيد لأهميته ومدى ملائمـة موقعـه ليصبح المركز الرئيسي لمدينة التحول العاصمة صنه من لمفاء وكانت المقومات كالتالي:

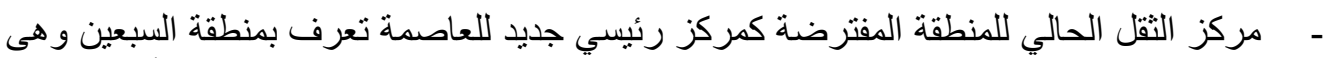

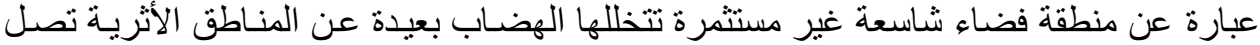

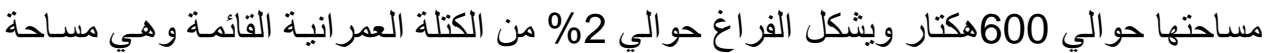
مناسبة لاستيعاب كل الفعاليات التخطيطية لقيام مركز حضري حقي حقيقي لمدينة التوسع.

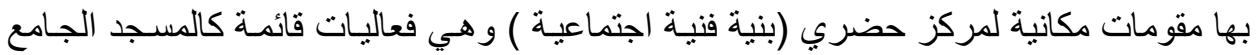

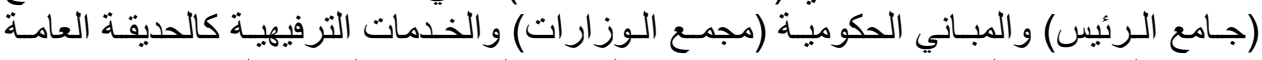

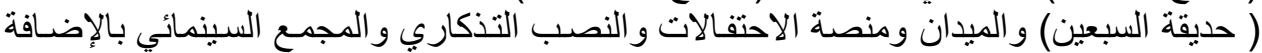

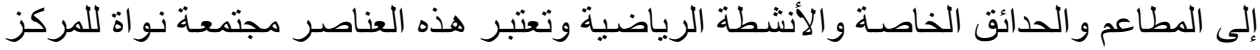
الجديد المفترض للعاصمة.

\section{2- - 12 - 1ائتج والتوصيات}

\section{1-12}

تمثنل المنطقة المركزيـة الحاليـة (منطقة التحريـر ) أهم منطقة حضـرية وتؤدي دور القلب إلا أنها

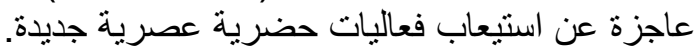

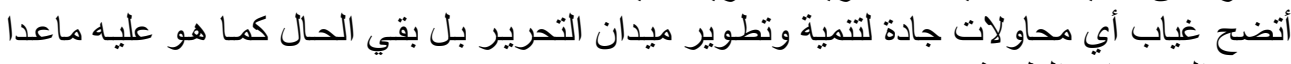
بعض التحسينات الطفيفة. ظهر مركز وسط المدينة التحرير المركز الفعلي النشط بين مجموع المر اكز وظهر متعدد الوظـائف ومتشنابك التخصص. ظهر التر ابط بين المر اكز ضعيفاً و أنها لا تعمل ككيان واحد كما ظهر المركز الرئيسي الحسالي لا

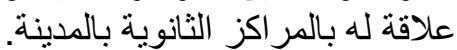

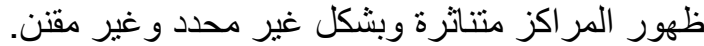

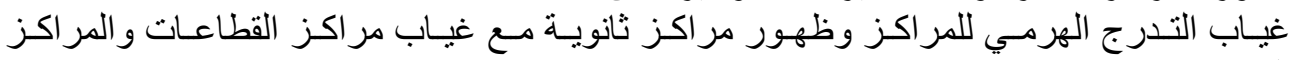
الرئيسية. ظهرت بقية المر اكز الرئيسية الأخرى المنافسة للمركز الرئيسي عبارة عن أسواق و لا ينطبق عليها صفة المر اكز الحضرية.

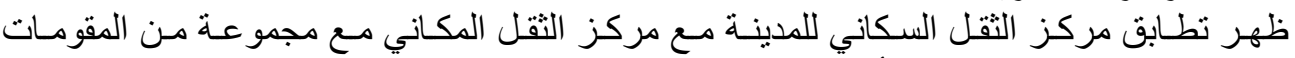
الحضرية في منطقة السبعين الأكثر ملائمة لإنشاء المركز مرئه الرئيسي الجديد. 


\section{2-12}

من مجموع الدر اسات و النتائج يمكن التوصل إلى التوصيات التالية:

\section{** تقوية المراكز القائمة}

• يتم تقوية المر اكز الحضرية الرئيسية القائمسة في المدينة مثل ( شميلة/ مذبح / الحصبة) لتصبح

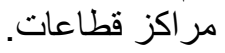

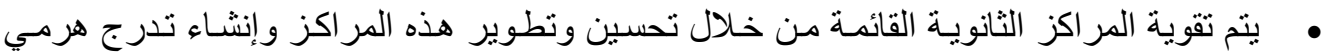
واضح لهذه المر اكز وربطها بالمر اكز الرئيسية.

\section{* *قوية المركز الرئيسي (منطقة التحرير)}

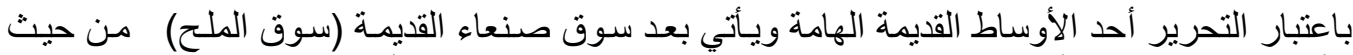

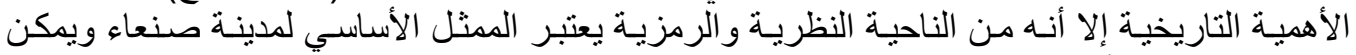

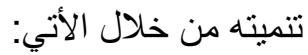

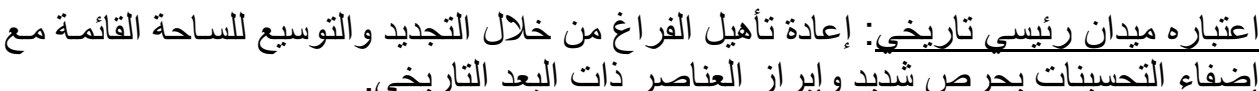

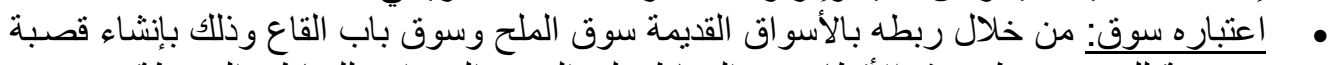

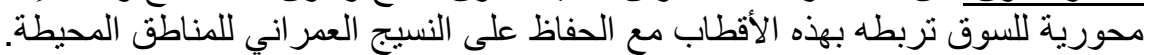

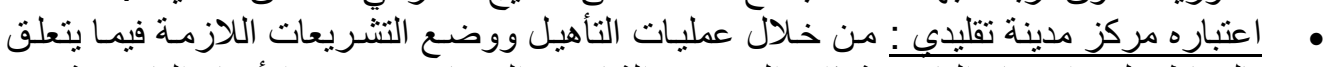

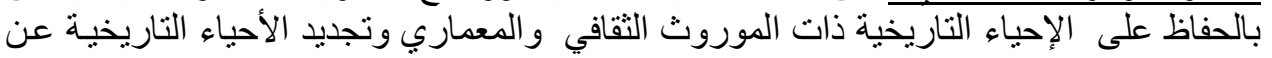

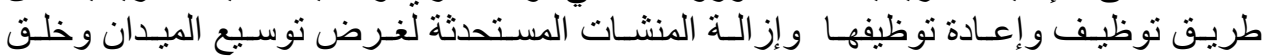
عناصرتناسب هذه الوظيفة.

\section{** إنشاء مركز جديد للمدينة}

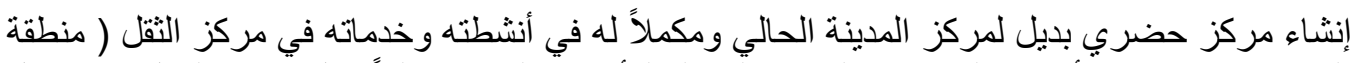

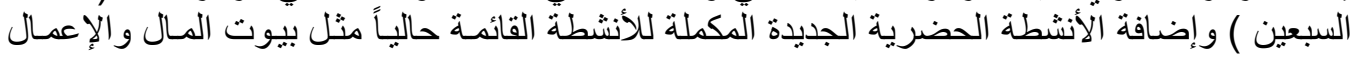

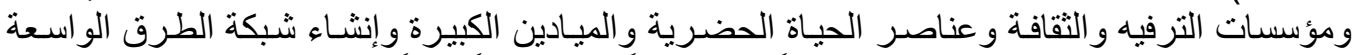

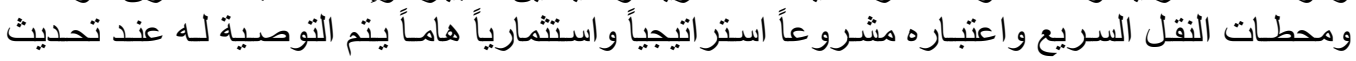

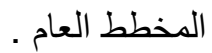

\section{(*** عادة توزيع شبكة المراكز بالمدينة}

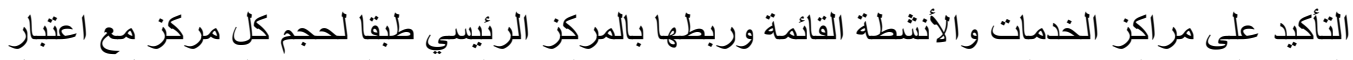

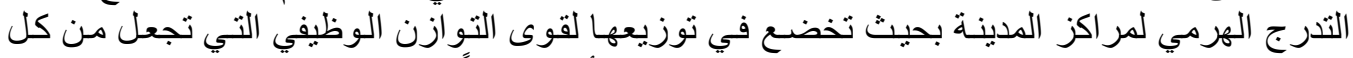

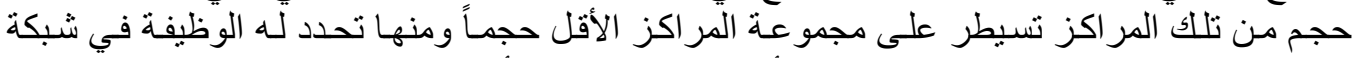

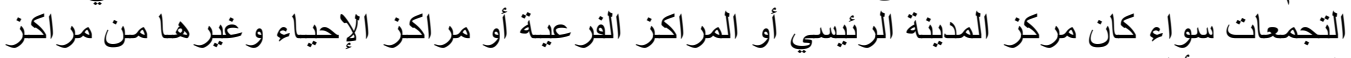

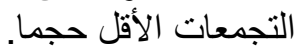




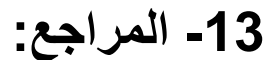 \\ 1- المخطط العام لمدينة صنعاء، العيئة العامة للتخطيط العمر اني و المساحة، 2005}

[2] Michail D, Beyand, Shopping Center Development, p. 78, Amazon press, USA : 2004.

[3] Kenneth B. Hall, Community by Design, New Urbanism for Suburbs and small Communities, p. 102, Amazon press, USA : 2004.

4- العو اضي حميد أسماء الأعيان الحضرية لمدينة صنعاء , مجلة الثوابت ، صنعاء، العدد 4, ص182, 2005

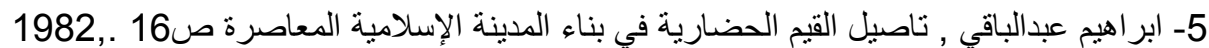

[6] Nasher Khalil -Conservation of the Architectural heritage in old sana'a, p. 74, Master thesis, Sttutgart uni. Garmany ,1989.

7- حسنين ابو زيد , التحو لات الحضرية في الهياكل العمر انية لدينة القاهرة- ص67 ك-ص69, رسالة دكتوراة، جامعة الاز هر ربن 1992

[8] Peroy: Development of center system ,p172,Budapest ,1971.

[9] Omer Akbr, Sanaa Neighbourhood and District,P34, GTZ,Ministry of Urban Planning, Sanaa, 1987.

[10] Berger Kampsax Sana'a Master Plan, MHUP v.2,p27 sana'a 1978.

[11] Cuban team ,Updating of the Master Plan of sana'a city,MCHUP,1998.

12- الغرفة التجارية والصناعية اليمنية، 2005.

13- العثاوي، عبدالحكيم , مدينة صنعاء تركيبها الداخلي و علاقتها الاقليمية ,ص 76- رسالة دكتور راه ، بغداد

.1996

14- الدـدجي، محمد سلام ، الخدمات العامة في الدـن اليمنية الو اقع و الاحتيـاج, مجلة العلوم و التكنولوجيا,

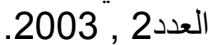

15- الهيثي, صبري فارس صالح فليح , جغر افية المدن, ص259 -260 , بغداد 1986. 